\begin{tabular}{|l|c|c||}
\hline Received: July 2019 & Accepted: August 2019 & Published: October 2019 \\
\hline \hline \multicolumn{2}{|c||}{ Article DOI: http://dx.doi.org/10.24903/sj.v4i2.319 } \\
\hline
\end{tabular}

\title{
Digital Quiz as Media to Review Material for English Education Students
}

\author{
Dyah Mukaromah \\ University of Technology Yogyakarta \\ dyahmukaromah@uty.ac.id \\ Anisa Mutoharoh \\ University of Technology Yogyakarta \\ anisfrust@gmail.com
}

\begin{abstract}
This study aims to explain the digital quiz to review the learning material. Its focus is to use digital media to support the learning process (reviewing material). Material Development is a subject that is reviewed by the student and the review done through Quizalize. A digital quiz that is so user-friendly and quite interesting. The participants of this research are sixteen students of English Education Department, from the University of Technology Yogyakarta; 4 males and 11 females. Qualitative data are obtained from the quiz that has been completed by the students. The result of this study shows that the display of the quiz is interesting. Quizalize provides analysis for each question. In addition, Quizalize also shows the result for each student, grouped students into categories based on their score. Quizalize accommodates students' needs in using technology. The researchers recommend Quizalize as a digital quiz that can be used by the teacher to review the material.
\end{abstract}

Keywords: digital quiz; review; material development; Quizalize

\section{INTRODUCTION}

Teachers are expected to have new innovations in learning. From only assigning students to listen, write, and do assignment become assigning students to actively express their ideas and think critically related to the learning material. From conventional methods to methods that stimulate students to think. The teaching method should be integrated together with appropriate media as an assistant on the application in the classroom (Halimah, Lustyantie, \& Ibrahim, 
2018; (Damico \& Krutka, 2018; Dukuzumuremyi \& Siklander, 2018; Paratore, O’Brien, Jiménez, Salinas, \& Ly, 2016). Teachers need to continue to use technology tools to improve the representation, adaptation, presentation and interaction with social studies subject matter. Several teaching methods, styles, strategies and software are used to design instructional materials for an effective visual presentation to ease the teaching and learning of a content (Rachman, 2016; Brown, 2015; Ivanović, Milićević, Aleksić, Bratić, \& Mandić, 2018) . Why does using media is important? It is indeed, expected to reach learning goals, teachers do not supposed to only use textbook plainly, they should be able to use interesting media such as games, chants, and quiz.

The quiz can be used by the teachers to figure out how far students master the material. The quiz is used as a reflection for the teachers to improve his teaching method or as a reference in determining the appropriate method. For students, it is very useful to find out how far they master the material. In other words, the quiz can be used to review the material.

Review material is usually done either at the beginning and at the end of the learning process. Review which is done at the beginning of the class usually aimed to brush up previous material. Whether review which is done at the end of the class aimed to emphasize the compulsory part of all the material on that day. Making summaries or answering short questions related to the material are things that teachers often used in reviews. Actually, there are many things that can be used by the teacher to design an attractive review. So the students will have high motivation in attending the review. One of them is using digital technology.

Digital technology can be used as media in the learning process. Moreover, Indonesia has entered the 4.0 digital era where technology is a tool facilitates all fields, including education. There are lots of applications and websites which can be used by students to assist them to learn. Educational applications provided on the internet give the opportunities to make the interaction between students and teachers in the virtual classroom and increase their motivation to learn (Fatimah \& Santiana, 2017; (Alvarez, Dal Sasso, \& Iyengar, 2017, 2018). Thus, teachers are able to use digital technology as a media to review material in the form of quizzes.

The research conducted by (Sanchez, Diego, \& Sanchez, 2017; Kazemipour, 2014; Li \& Zou, 2017) find out whether quizzes can be an effective tool for learning in an EFL environment due to repeated testing. In this study, the authors use an experimental method. The participants of the research are two groups of Spanish students in "English Language I" with an intermediate level in the English language equivalent to B1. To check the equivalent two 
groups are given a Level Test at the beginning of the semester. Pre-test and Post-test are given in both the experimental group (the group who takes quizzes) and the control group (the group who does not take quizzes). Treatment is given to the experimental group before a post-test. The result shows that the group that is given a quiz has a better result rather than the group who does not.

The second research is conducted by Cook \& Babon (2016) has examined the role of online assessments based on prescribed preparatory materials in enhancing student learning outcomes. Qualitative and quantitative data from the University's LMS and SES (Subject Experience Survey) are used to evaluate the role and the value of the quizzes. The SES data from three years are used: 2013, 2014, and 2015. Quantitative data are drawn from one fixedchoice SES (Subject Experience Survey), which uses a Likert scale from 1 to 5. Qualitative SES data are analyzed with specific attention for the terms "quiz", "test", "online" and "LMS". The result of this research is that online quizzes are an effective mechanism, enhancing active learning and efficiency of the time.

The third research is conducted by Sawarkar et al. (2015) efficacy of quiz over conventional teaching and assess the student's perception regarding intervention, to assess the perception of students towards quiz as a teaching method and to assess the retention of knowledge by quiz method. The sample of this research is 60 students of B.A.M.S first year batch 2014-15. The sample is divided into two groups. Control group and study group. The control group is taught by didactic lecture and study group with self-study and reinforcement through the quiz. Sandhi Sharir is a selected topic for intervention. Both groups are given pretest to assess their prior knowledge. The first post-test is after completion of the topic and the second post-test is conducted after 15 days to assess the retention of knowledge. The result of this study is the students agree on the utility of quiz, the quiz appears to foster effective learning in small groups and the intervention in the form of the quiz is effective and can be implemented. This research also recommends that the quiz can be implemented as a teaching tool.

\section{METHODOLOGY}

Material Development subject is the material that is reviewed using Quizalize. The students have to answer ten questions about Material Development through Literature. The material has been studied in the previous meeting. The material is about the use of various types of literature for teaching. Such as nursery rhymes, folklore, short story, and legend story. 
The participants of this research are 16 students of semester six (6) English Education Department of the University of Technology Yogyakarta academic year 2019. Those 16 students contain 5 male students and 11 female students.

Data are obtained from the result of the participants conducting material reviews using quizzes. The participants are students who have to learn about material development through literature. On the sixth meeting, they have to bring a laptop or smartphone which has internet access. The lecturer asks the students to access quizalize.com to do a review from their own laptop or smartphone. The teacher gives them a code to access the class. The students have to answer ten questions that the teacher has made on Quizalize.

Then, the data are analyzed using descriptive qualitative methods. Qualitative data analysis involves organizing, accounting for and explaining the data (Cohen, Manion, \& Morrison, 2007). Meanwhile, Lambert \& Lambert (2012) argue that a qualitative descriptive approach is very useful when researchers want to know regarding events, who were involved, what was involved, and where did take place. It means that the data are analysed to know how digital media can be used as media to review the material and to explain how the use of Quizalize.

\section{FINDINGS AND DISCUSSION}

\section{Findings}

The procedure before using Quizalize to review material

The students go to quizalize.com and log in as a student.

\section{The easy way to differentiate your teaching}

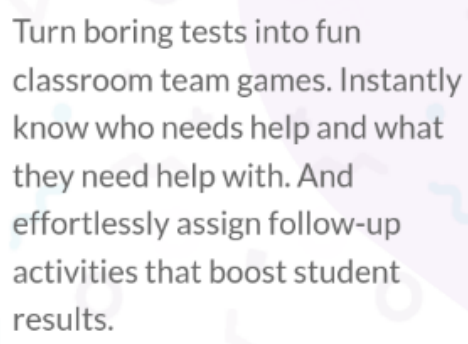

Turn boring tests into fun classroom team games. Instantly know who needs help and what they need help with. And effortlessly assign follow-up activities that boost student results.

Figure 1. Log in as students 
Enter the class code. The class has been created by the teacher. In the class there is a quiz that the student should answer. Someone who does not know the class code can't access the quiz. The teacher also can create classes not only one subject in Quizalize. Here the subject is Material Development, so the students click Material Development subject to do the quiz. It means that Quizalize not only for one subject. As long as the teachers have account to access as a teacher, they can create every subject quiz. The class code of this quiz is: gpg8347.

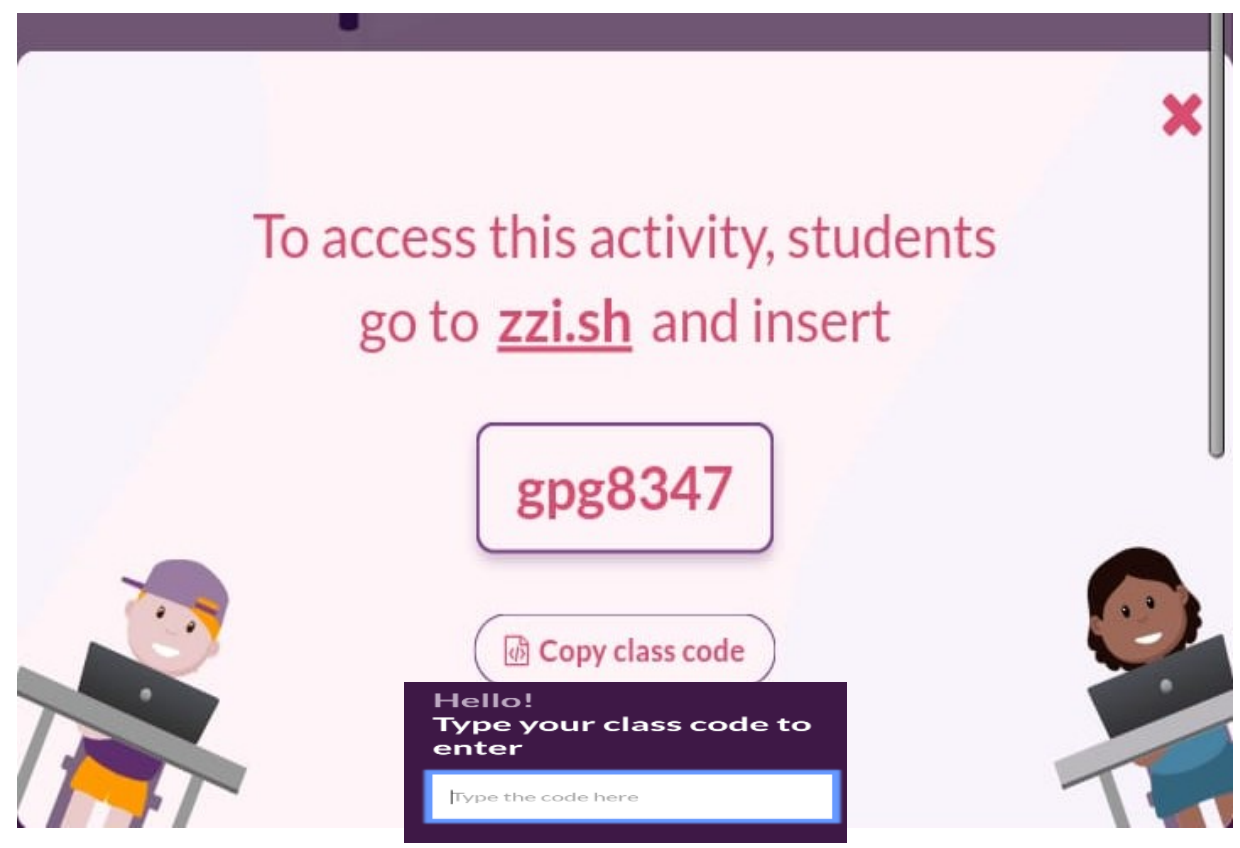

Figure 2. Class code

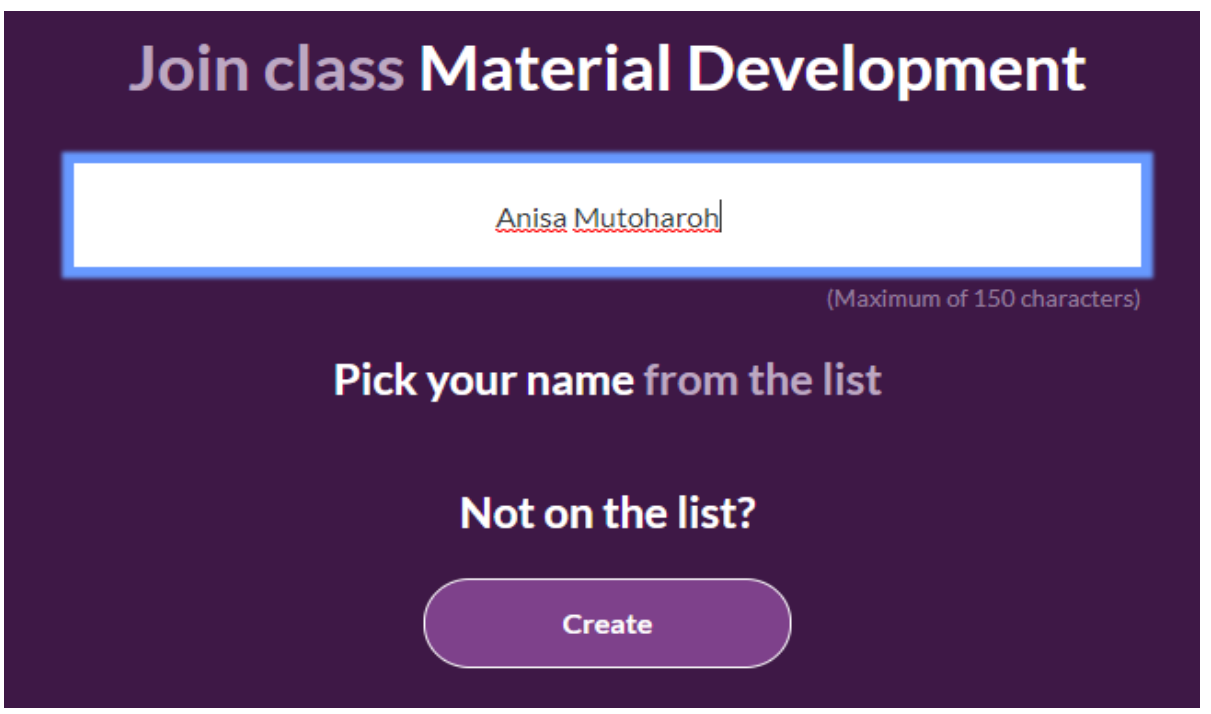

Figure 3. Create name

After that the students enter their name and ready to play the quiz. 
The strength of using Quizalize to review material

The display of the questions is interesting

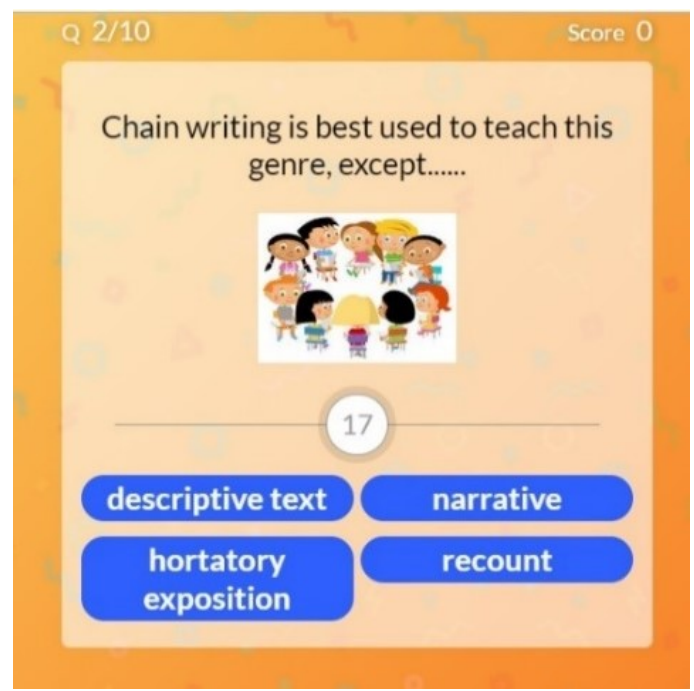

Figure 4. The display of the question

In the top left corner, there is Q 2/10. It means that it is question number 2 from 10 questions. In the top right corner, there is a score that has been obtained. Number 17 in the middle is the time allotment to answer the question. It keeps counting as the students take time to answer. When the time is up, the students will not get a point. When the students answer the question correctly there will be music and stars that indicate greeting to congratulate them, yet when the answer is wrong, there will be a correction.

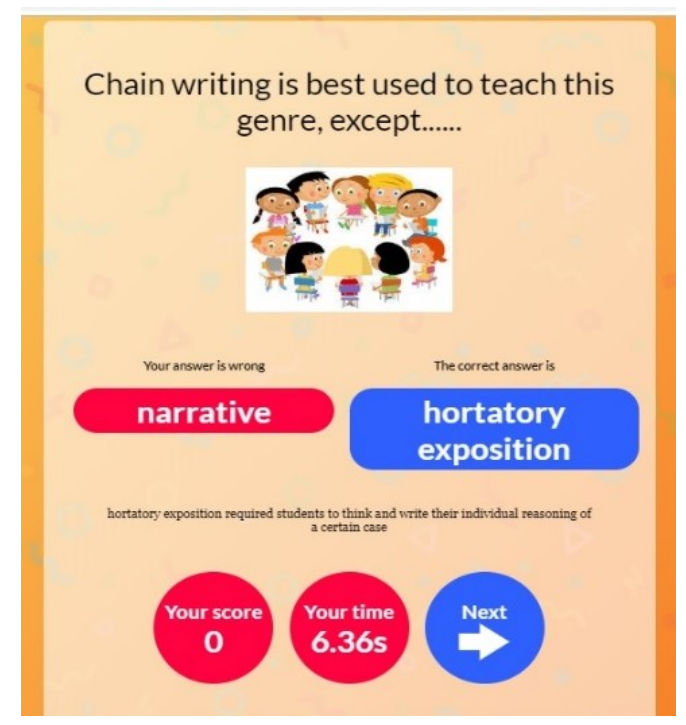

Figure 5. The result of each question

If the students get the wrong answer, they will directly know the correct answer. It is also containing the explanation of what is the correct answer and the time that the students used to answer the question. 


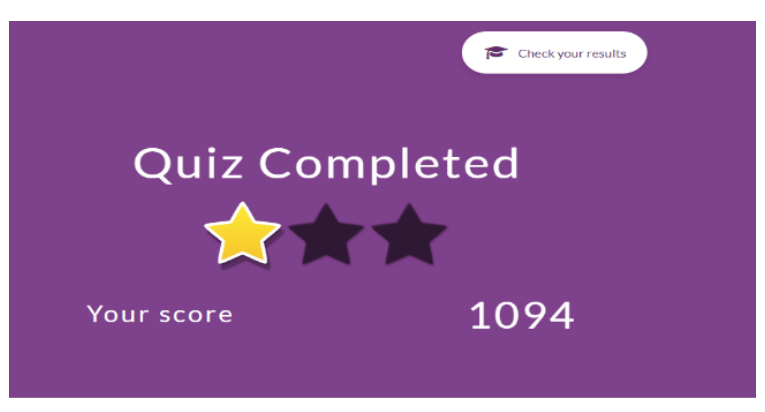

Figure 6. Reward

After all the questions answered, the students get a reward from what they have completed.

The result of the quizzes

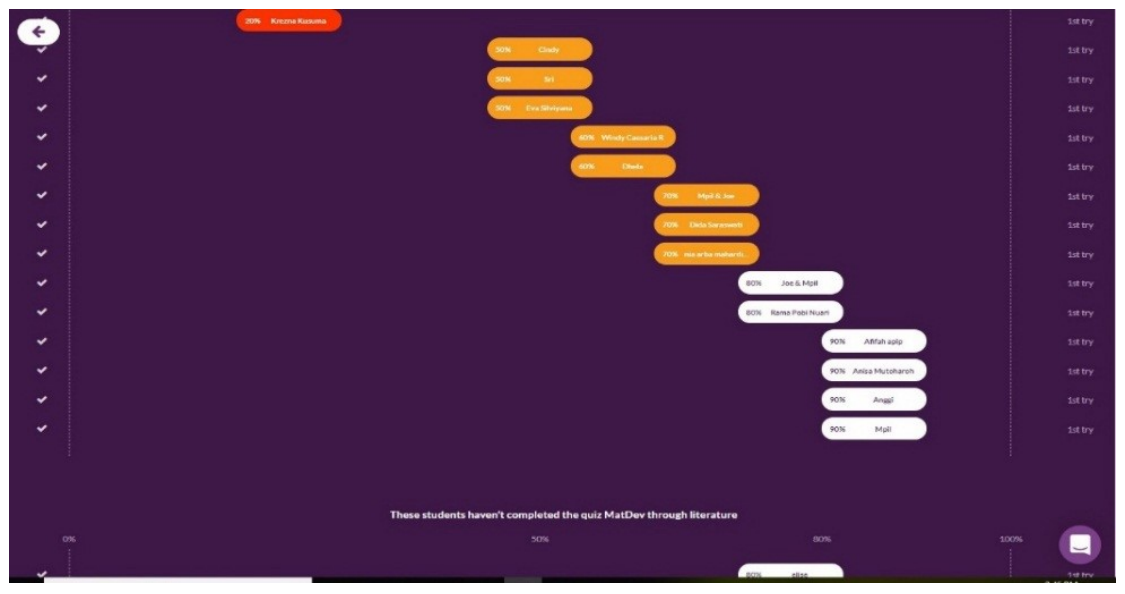

Figure 7. Students' result

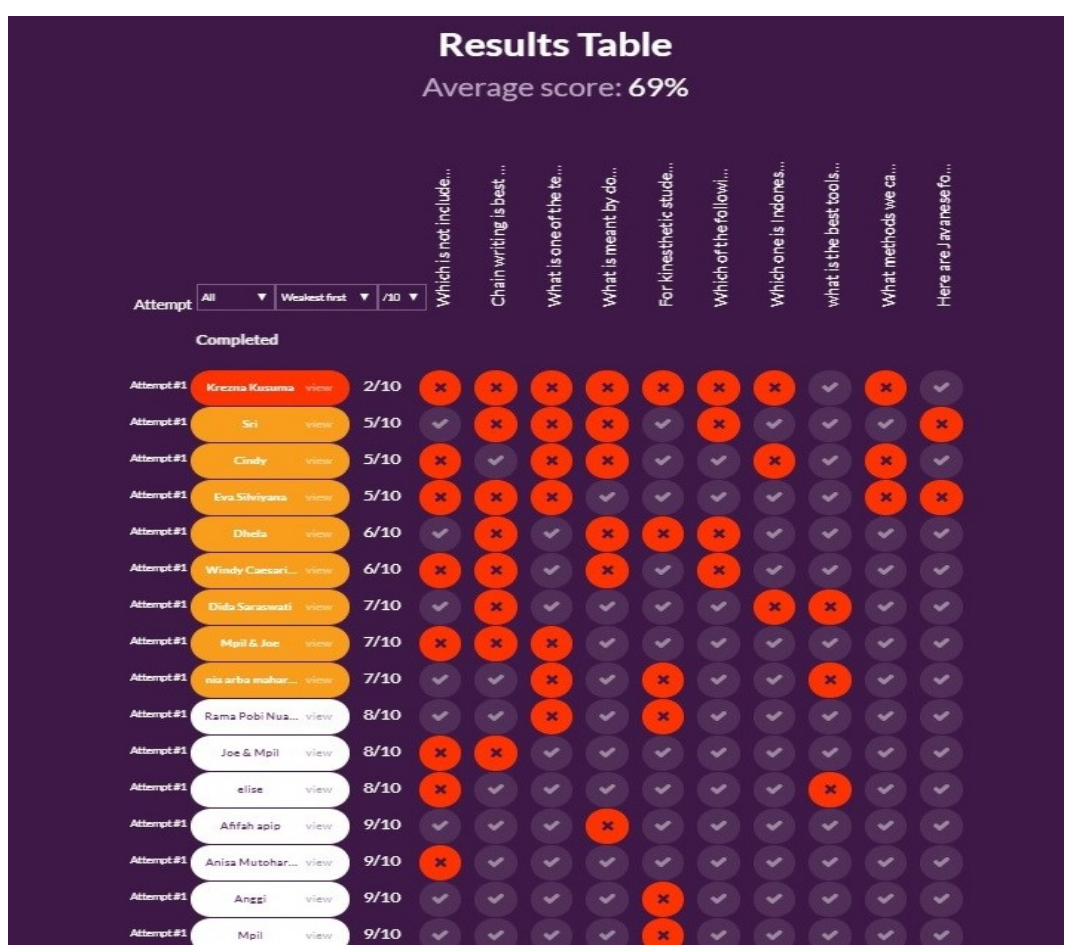

Figure 8. Result Table 
The red one on the top left corner indicates the student who needs help. It means that the student who gets a red box should study harder. He has not mastered the material yet. The eight students get a yellow box means that they almost reach the target. They only need little improvement in this subject. The last is the students who got a white box. It means that they are strong enough in this material. They have passed the subject. Students need to answer at least eight questions correctly to pass the material. The students who get seven correct answers stand in 'almost there' students. Five to seven correct answers are in 'almost there' students. Four to zero correct answers are in 'need help' students. The result table contains each student's incorrect answer. The table shows the average score for this quiz that is $69 \%$. This table also shows how many correct numbers that the students can answer. Like the red box, Kresna Kusuma (The name of the student) gets $2 / 10$. It means that he only gets 2 correct answers from 10 questions. The sentences that are standing above are the questions. The red $\mathrm{X}$ indicates which questions that the students get the wrong answers. Kresna Kusuma (The red box) answers incorrectly on the number $1,2,3,4,5,6,7$, and 9 . He answers correct on the number 8 and 10 . The result is arranged from the weakest one to the strongest one.

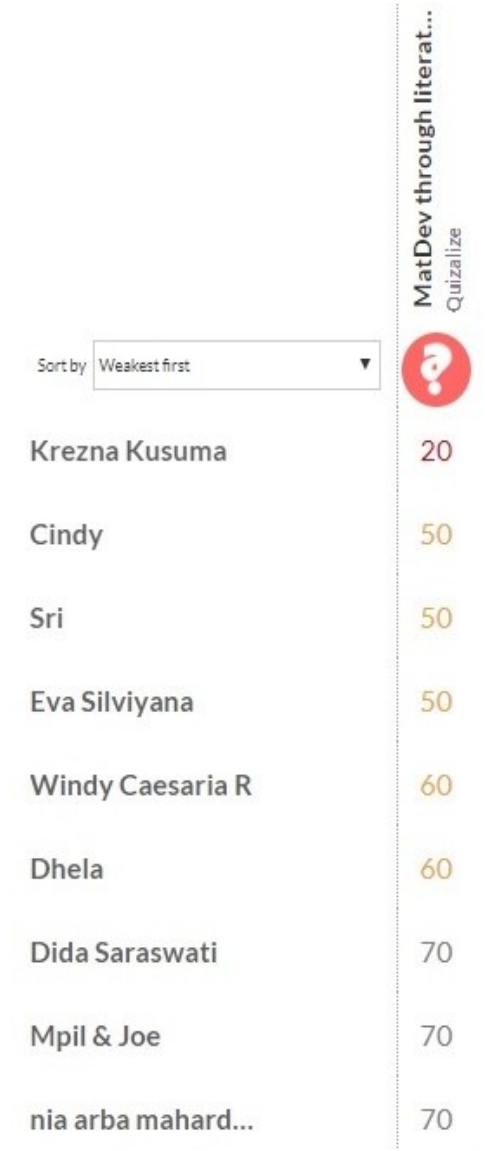

Figure 12. Score 
It is the result in the form of the number. This application not only offers the result analysis but also the score number of each student. This application puts students' quiz achievement in number format.

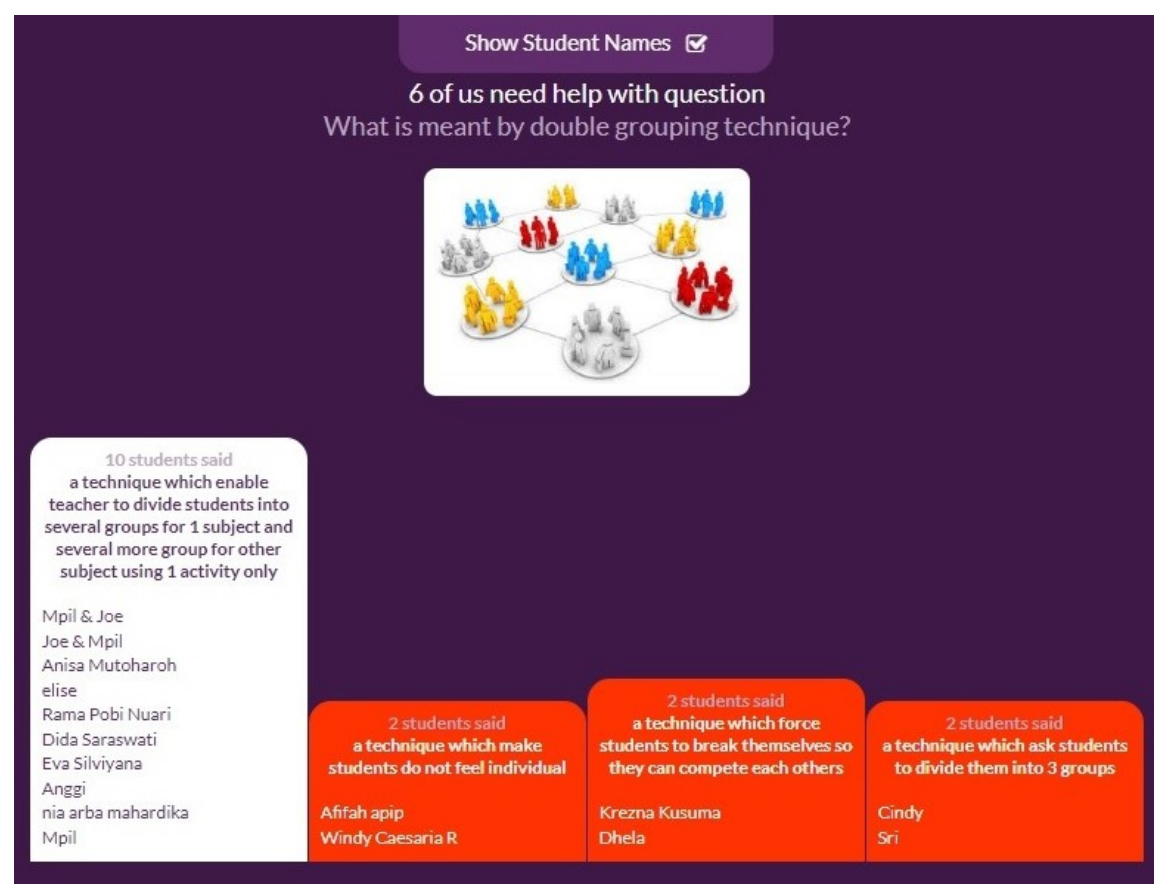

Figure 13. Analysis of each question

Here, the question is "What is meant by double grouping technique?". 6 students answer incorrectly and 10 students answer correctly. The white box is the correct answer. The answer is "a technique which enables teacher to divide students into several groups for 1 subject and several more group for either subject using 1 activity only". 2 students answer "a technique which makes students do not feel individual". 2 students answer "a technique which forces students to break themselves so they can complete each other". 2 students answer "a technique which asks students to divide them into 3 groups". 


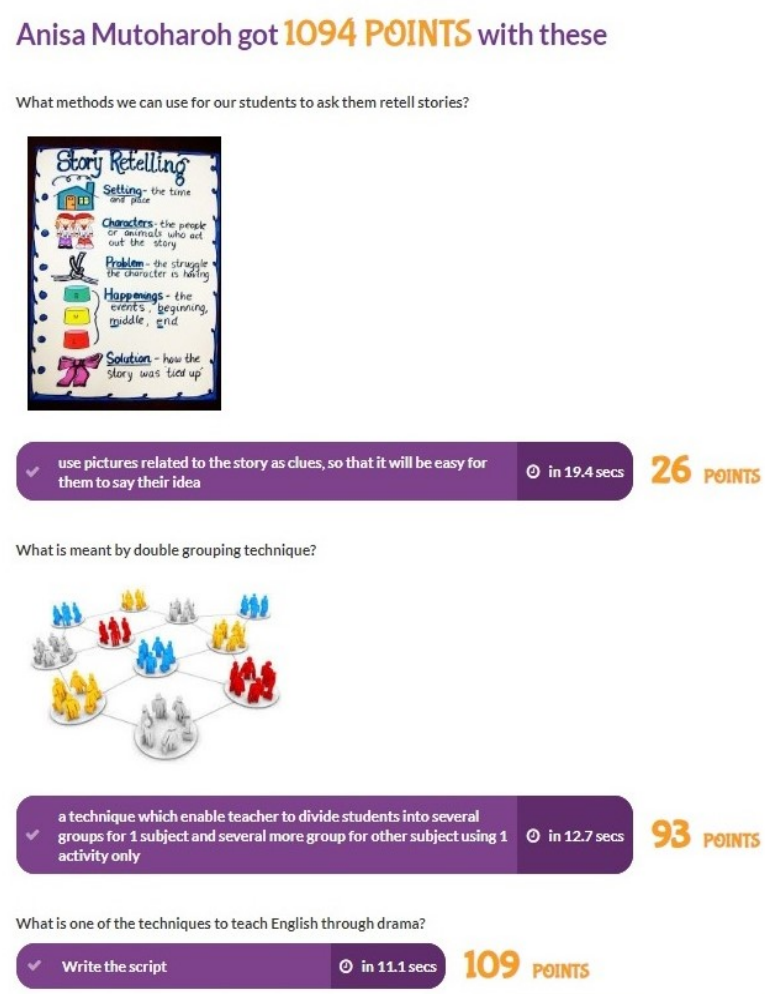

Figure 14. Each student result

Not only the teacher can recognize the result, but the students also can see their own results. In here, Anisa Mutoharoh (one of the students) gets 1094 points with several notes. Quizalize shows the detailed point from each question and detailed time. The faster the students answer, the bigger the score they will get. Anisa gets 26 points with 19.4 seconds in questions "what method we can use for our students to ask them to retell stories?". The analysis applies to all questions.

\section{Discussion}

There are many strong points possessed by Quizalize, as described above. The display is so interesting since the teacher can post supporting pictures in the questions. The teacher can modify the question as interesting as possible. The display of the question in Quizalize shows the display of the question that has been modified by the teacher. The picture is related to the question. Interesting packaged questions will motivate students to be interested in reading and answering the questions. The teacher can also set the time allotment that the students need to answer the question. If there is no time remains and the students have not answered yet, the next question will automatically appear substituting the previous question. It helps the teacher to manage the time effectively. Quizalize also shows the reward the students get. The reward (in the form of a star) will be earned based on the students' correct number and time that they 
use. Reward cheers the students up. It can be a motivation for the students to get more stars. If they want more stars, they should study the material harder.

Quizalize provides the direct results of the quiz. Through this direct result, the teacher can recognize the students. The result of the quizzes shows which students need a personal approach, which students have understood the material, and which students need some improvement. The teachers are no longer spending their time to check students' results one by one. It is the direct result that really helps the teachers, which discussion that need more explanation and which discussion that is enough explanation. The questions that students mostly answer incorrectly are the discussion that needs more explanation. The questions that students mostly answer correctly are the discussion that has enough explanation.

The result table shows that the teachers do not need to worry about which questions that the students answer incorrectly. Although each student will get a different arrangement of the quiz number, Quizalize provides analysis of each question and show the name of the students. When this application only analyses the result, it makes the teachers work twice to decide how many scores that the students get. Quizalize helps the teacher to know the score of each student quickly, especially if the teacher has a large number of students from many classes. Surely if the quiz is corrected manually, it will take a longer time.

Quizalize does not only give benefit to the teachers as their media to create a quiz, but Quizalize also gives the students an understanding of which material that they master and which material they have to study more. It also shows us the detailed result of each question, how many times the students need to answer each question is shown on the result. It can be accessed not only by the teacher but also by the students in their Quizalize account. By looking at the evaluation, it is expected to give clear points calculation for each question.

\section{CONCLUSION}

Based on the discussion and result, the researchers found that teachers can use digital media in the learning process. Quizalize is one of the digital media that the teacher can use. Quizalize offers interesting questions display and direct results. It can make learning effective. Through Quizalize, the teacher can manage their own quiz review creatively. It makes the teacher be able to recognize which students need help and which student has mastered the material. Quizalize also offers the students to see their results. Based on that fact, the researchers recommend Quizalize as a digital quiz especially to review the material, considering the benefits that Quizalize has. 


\section{BIBLIOGRAPHY}

Alvarez, A. G., Dal Sasso, G. T. M., \& Iyengar, M. S. (2017). Persuasive technology in teaching acute pain assessment in nursing: Results in learning based on pre and posttesting. Nurse Education Today, 50, 109-114.

https://doi.org/https://doi.org/10.1016/j.nedt.2016.12.019

Alvarez, A. G., Dal Sasso, G. T. M., \& Iyengar, M. S. (2018). Mobile persuasive technology for the teaching and learning in surgical safety: Content validation. Nurse Education Today, 71, 129-134. https://doi.org/https://doi.org/10.1016/j.nedt.2018.09.030

Brown, J. P. (2015). Complexities of digital technology use and the teaching and learning of function. Computers \& Education, 87, 112-122.

https://doi.org/https://doi.org/10.1016/j.compedu.2015.03.022

Cohen, L., Manion, L., \& Morrison, K. (2007). Research Method in Education Sixth Edition. London: Routledge.

Cook, B. R., \& Babon, A. (2016). Active Learning through Online Quizzes : Better Learning and Less (busy) Work. Journal of Geography in Higher Education, 41(1), 1-15.

Damico, N., \& Krutka, D. G. (2018). Social media diaries and fasts: Educating for digital mindfulness with pre-service teachers. Teaching and Teacher Education, 73, 109-119. https://doi.org/https://doi.org/10.1016/j.tate.2018.03.009

Dukuzumuremyi, S., \& Siklander, P. (2018). Interactions between pupils and their teacher in collaborative and technology-enhanced learning settings in the inclusive classroom. Teaching and Teacher Education, 76, 165-174. https://doi.org/https://doi.org/10.1016/j.tate.2018.08.010

Fatimah, A. S., \& Santiana, S. (2017). Teaching In 21 Century: Students-Teachers' Perceptions of Technology Use In The Classroom. SCRIPT Journal of Linguistics and English Teaching, 2(2), 125-134. https://doi.org/http://dx.doi.org/10.24903/sj.v2i2.132

Halimah, Lustyantie, N., \& Ibrahim, G. A. (2018). Students' Perception on The Implementation of Orai Application in CLL Method in Teaching Speaking. JEELS, 5(1).

Ivanović, M., Milićević, A. K., Aleksić, V., Bratić, B., \& Mandić, M. (2018). Experiences and perspectives of Technology-enhanced learning and teaching in higher education Serbian case. Procedia Computer Science, 126, 1351-1359. https://doi.org/https://doi.org/10.1016/j.procs.2018.08.086

Kazemipour, S. (2014). Comparing the Outcomes of Two Types of Corrective Feedback on EFL Classes' Final Exam. Procedia - Social and Behavioral Sciences, 98, 876-881. https://doi.org/https://doi.org/10.1016/j.sbspro.2014.03.495

Lambert, V. A., \& Lambert, C. E. (2012). Editorial : Qualitative Descriptive Research : An Acceptable Design. Pacific Rim International Journal of Nursing Research, 16(4), 255-256.

Li, W., \& Zou, W. (2017). A study of EFL teacher expertise in lesson planning. Teaching and Teacher Education, 66, 231-241. https://doi.org/https://doi.org/10.1016/j.tate.2017.04.009

Nassaji, H. (2015). Qualitative and Descriptive Research : Data type versus Data Analysis. Language Teaching Research, 19(2).

Paratore, J. R., O’Brien, L. M., Jiménez, L., Salinas, A., \& Ly, C. (2016). Engaging 
preservice teachers in integrated study and use of educational media and technology in teaching reading. Teaching and Teacher Education, 59, 247-260.

https://doi.org/https://doi.org/10.1016/j.tate.2016.06.003

Sanchez, M. J., Diego, C., \& Sanchez, A. F. (2017). Using quizzes to assess and enhance learning of English as a foreign language. Revista Española de Lingüística Aplicada, 30(1), 325-341.

Sawarkar, G., Kuchewar, V., \& Desai, P. (2015). Efficacy of Quiz as a Teaching and Learning Tool for First Year Ayurved Students. JHSE, 2(2), 92-95. 